\title{
Relationship between Physical Bullying and Age in Albanian Teenagers
}

\author{
Dr. Leticja PAPA-GUSHO \\ Pedagogy-Psychology Department, \\ Social Science Faculty, \\ Tirana University \\ Ipapagusho@yahoo.co.uk
}

\begin{abstract}
Each year millions of children and teenagers experience the humiliation and devastating effects of bullying. According to different studies bullying begins in preschool years, peeks in early adolescence, and continues, but with less frequency, into the high school years. The main aim of this paper is to examine the relationship between physical bullying and age in Albanian teenagers. The participants in this study were 400 students of senior year from High Schools of Tirana, Shkodra, Elbasan, Durrës and Korça. The approach for this study was quantitative and statistical analyses for this research were performed using the SPSS program. For gathering the data the retrospective bullying questionnaire was used. For this article only closedended questions are considered. The relationship between the perceptions of senior students about physical bullying and their age was revealed using Spearman's rho coefficient correlation. In conclusion, from the statistical analysis it was revealed that there is a strong negative correlation between the physical bullying and age, $r s=.-865, n=400, p=.000 ; p<.0005$, that indicates that growth in age strongly correlates with the decrease of physical bullying.
\end{abstract}

Keywords: physical bullying, teenagers, age.

\section{Introduction}

Bullying is a subjective experience and can take many forms. Accounts of children and young people, backed up by research, identify bullying as any behavior that is: harmful, carried out by an individual or a group; repetitive, willful or persistent; an imbalance of power, leaving the person being bullied feeling defenseless. (Robinson \& Maines, 2008).

Meanwhile, Askew (1989), defines bullying as a continuum of behavior which involves the attempt to gain power and dominance. According to other authors, bullying is systematic, occurring repeatedly, and it embraces a variety of hurtful actions, including name-calling, social exclusion, having money taken or belongings damaged as well as more obvious physical forms such as hitting and kicking. (Bowers, Smith \& Binney (1994)

But who is involved in school bullying? School bullying almost always involves the bullied, bully or bullies and bystanders. The researches show that any child or young person can be a victim of bullying, regardless of his or her gender, ethnicity, age or socio-economic background. However, the researchers have also discovered that the bullied most often stand out from their peers in some way. Most often by; physical differences including race, ethnicity, disability and even things such as hair color or the size of the nose; lower socio-economic background; sexual orientation; being new in the class; excellent or poor academic performance.

Bullies are often children who have a strong desire to establish control over other children and generally don't have sympathy for their victim's feelings. Often, the bullies are bullied or abused themselves. Not all children and young people, however, are deliberately hurting others. They sometimes aren't aware that teasing, calling names, exclusion, etc. is causing a serious distress to other child. (www.anti-bullyingalliance.org.uk).

According to Lee, (2005), there are three basic types of bullying, physical bullying, verbal bullying and social bullying. All this can be overt and covert bullying forms.

Physical bullying. Physical bullying is more than punching and kicking and can assume indirect forms, including taking possessions, damaging property or school work with a view to disempowered, i.e. there is a physical manifestation of the 
bullying but no physical pain. Included in such forms of bullying is extortion, where threat of violence leads to the victim giving up money or possessions, and the threat of violence or gestures and body language that is intimidating.

Verbal bullying. This is one of the most common forms of bullying as it can have an immediate impact, often in front of an audience, with very little effort on the part of the perpetrator.

Social bullying. This form of bullying incorporates deliberate exclusion from social groups or intimidation within the group. (Lee, 2005)

In this perspectives it is a very interesting propose of the ecological framework within which bullying occurs. Ecologicalsystems theory purports that all individuals are part of interrelated systems that locate the individual at the center and move out from the center to include all systems that affect the individual (Bronfenbrenner, 1979, in Espelage \& Swearer, 2009).

According to this theory, the child is an inseparable part of a social network comprised of four interrelated systems: microsystem, meso-system, eco-system, and macro-system. The micro-system includes the child's relationship with one system (e.g., home or classroom or playground). The micro-system depicts the child's immediate interaction with others, and includes others' reactions to bullying behaviors. This conceptualization of the micro-system also includes the status of the child along the bully/victim continuum. Thus, the bully, bully-victim, victim, or bystander interacts with others in his or her social environment, and this interaction either exacerbates or mitigates bullying and/or victimization behaviors. Mesosystem includes the interrelationship between systems in the child's life (e.g., home and school). Meso-system depicts the congruence between two or more environments, such as the congruence between home and school regarding bullying behavior. The eco-system includes influences from other contexts, such as the effect of a school district's anti-bullying policy or parental involvement in the school system. Finally, the macro system is the influence of cultural mores, such as societal attitudes toward bullying behaviors.

According to O'Moore and Minton (2005), steps towards means by which bullying incidents may be investigated and recorded are as follows:

1. Co-ordination of anti-bullying countering strategies. Some schools have found it helpful to nominate an individual staff member, or small group of members, who are responsible for the co-ordination of anti-bullying strategies within the school. Here, voluntarism is probably the best means of selection; having stated this, it is of course advisable that the coordinator should be a permanent and senior member of staff.

2. Talks to the whole student body. Periodically and when the opportunity presents itself to address the entire school body - and preferably at least once a term - students should be reminded that the school has an active anti-bullying policy, and that bullying behavior is not accepted in this school.

3. The essentials of reporting. When someone makes an allegation of having been bullied, or reports that someone else has been bullied, the most important thing (in the initial phases) is to attend to that person's safety needs. Communicating that we 'believe' the complainant is perhaps too strong - after all, individuals' perceptions will differ, and not every incident is unambiguous - but we should communicate that we accept what the complainant has to say. The complainant's statements should be listened to actively; and with no interpretation, the complainant's specific grievances - particularly those concerning concrete events-should be recorded in writing, and kept on record.

The main idea of this article is to show the relationship between the physical bullying and age in Albanian teenagers.

\section{Methodology}

\section{Procedure and sample}

For this study a correlation research design was used. The gathering of the data was done through a survey process. According to Creswell, (2003), a survey is a process that is used to collect data from a sample or a population in order to describe the attitudes, opinions, behaviours, or characteristics of the population under investigation. 
The general population that served for this sample is made of senior year students who were frequenting the full-time 20142015 academic years from High Schools of Tirana, Shkodra, Elbasan, Durrës and Korça. From this population it was taken a sample of 400 participants. (Cohen, Manion \& Morrison, 2005)

The stage probability sample is used to select the sample from this population. It involves selecting the sample in stages; that is, taking sample from sample. In other words, with the stage selection sample, firstly it was selected a number of cities at random, then within the selected cities, it was randomly selected a number of schools. Within selected schools senior years were chosen. Finally, a number of students were selected randomly out of the students of the senior year. By means of this method was selected even the sample that represents all the population features. The sample of 400 students is composed from 168 boys and 232 girls, or $42 \%$ were boys and $58 \%$ were girls. The largest number of participants, $79 \%$ was 18 years old, followed by the students who were 19 years old, which comprise $21 \%$ of the entire sample.

The following were the most important criteria inclusion in the sample:

-The participant should be a senior year student in the high school in these cities.

- The participant should be really willing to participate in the research project.

\section{Instrument and its reliability}

The instrument used for the gathering of the data is a questioner made of some rubrics. The questionnaire was presented to 400 respondents who in 20-25 minutes completed it. Initially participants were informed about the purpose of the study and clarified that the survey data would be used only for academic purposes. Given that the perception of senior year students for the physical bullying and their age are the only focus of this article, only these elements of the questionnaire will be presented. A retrospective bullying questionnaire is designed to measure the perception of bullying of senior year students (National Centre for Injury Prevention and Control). Three rubrics with similar questions are designed. Firstly the respondents are asked about the time when they were in primary school, second when they were in the secondary school, and in the third rubric the respondents are asked about being bullied when they were in the high school. All items are arranged in a Likert scale, where students should circle the answer from never happened, rarely happened, sometimes happened, frequently happened, and constantly happened according to their level of agreement. Thus, items such as, "I was pushed or shoved", "I was hit or kicked hard ", "Students crashed into me on purpose as they walked by", "My property was damaged on purpose", "Something was thrown at me to hit me", "I was threaten to be physically hurt or harmed", are used to measure the perception of students about being bullied during school years. From the score calculations, for a seven item scale, using a response scale from 1 to 5 , the minimum value would be 7 and the maximum value would be 35 . A mean score of 28.8 or higher indicates a high level of perception of senior year students for physical bullying. A mean score between 16.4- 25.7 indicates a mild level of perception of senior year students for physical bullying. A mean score below 16.3 indicates a low level of perception of senior year students for physical bullying. Furthermore, Cronbach's alpha was run in order to assess internal consistency reliability for the scale used to collect the data. This scale, has a good internal consistency, with a Cronbach's alpha coefficient reported .74.

\section{Data analysis}

The data gathered from the survey was downloaded into the computer statistical package SPPS, version 16 . The data have been investigated for reliability and normality, as well as for missing data. Descriptive statistics, such as sample size, frequency and mean, were used to describe the characteristics of the sample and the perception of the senior students from the high school about physical bullying. Preliminary analyses were performed to ensure no violation of the assumptions of normality, linearity and homo-scedasticity. From the analyses it resulted that not all the data meet the assumption of the parametric statistics. For this reason non-parametric statistics were used (Pallant, 2010). For this reason the relationship between physical bullying and age was investigated using Spearman's rho coefficient.

The following table provides a summary of variables and the analytic procedures related to the paper question. 
Table 1. Paper question, variables, and analytic procedures

\begin{tabular}{|l|l|l|}
\hline Paper Question & Variables & SPSS Procedures \\
\hline $\begin{array}{l}\text { What are the perceptions of the students of the } \\
\text { senior year about being physical bullied during } \\
\text { the school time and the relationship between this } \\
\text { perception and age? }\end{array}$ & - Perception of the students of the & senior year about being bullied. \\
\hline
\end{tabular}

\section{Sources of error}

This research was carried out in order to minimize non real results. Like most of the studies made in the field of education, even this one is self-report based. As a result, the findings depend even on the students' acquisition of the questions in the survey as well as on the degree of sincerity they have completed the instrument with.

\section{Research ethics}

All the stages of research ethics have been followed during the implementation of this study. It has firstly taken the permission of the structures in charge of the schools where the instrument was conducted. Subsequently, a sensitization of the research and its goal was done to the participants before they filled the instrument. They were guaranteed anonymity and asked whether they wanted to participate voluntarily in the study. Furthermore, participants who did not want to be part of the study were not given the instrument.

\section{Results and discussion}

Table 2. Mean scores and standard deviation on perception of the students about physical bullying

\section{Descriptive Statistics}

\begin{tabular}{|c|c|c|c|c|c|c|}
\hline \multicolumn{2}{|l|}{ Age } & $\mathrm{N}$ & Minimum & Maximum & Mean & Std. Deviation \\
\hline \multirow[t]{2}{*}{$7-10$ years old } & Physical Bullying & 198 & 19 & 35 & 30.03 & 3.28 \\
\hline & Valid N(listwise) & 198 & & & & \\
\hline \multirow[t]{2}{*}{$11-14$ years old } & Physical Bullying & 122 & 12 & 28 & 20.77 & 3.23 \\
\hline & Valid N(listwise) & 122 & & & & \\
\hline \multirow[t]{2}{*}{$15-18$ years old } & Physical Bullying & 59 & 12 & 19 & 14.81 & 2.31 \\
\hline & Valid N (listwise) & 59 & & & & \\
\hline
\end{tabular}

Table 2, illustrates the mean scores and standard deviation regarding the perception of students about physical bullying during the school years. Thus, when the respondents were 7-10 years old their perception about physical bullying was ( $M$ $=30.3, \mathrm{SD}=3.28)$, when the respondents were $11-14$ years old their perception about physical bullying was $(\mathrm{M}=20.77$, $S D=3.23)$ and when the respondents were $15-18$ years old their perception about physical bullying was $(M=14.81, S D=$ 2.31).

As we can see, from the data the mean scores of perception for physical bullying in the period of 7-10 years old is 30.03 and this mean score is between 28.8- 35. This data indicates a high level of perception of senior year students for physical bullying when they were 7 to 10 years old. The mean scores of perception for physical bullying in the period of 11-14 years 
old are 20.77 and this mean score is between 16.4- 25.7. This data indicates a mild level of perception of senior year students for physical bullying when they were11-14 year old.

The mean score of perception for physical bullying in the period of $15-18$ years old is 14.81 and this mean score is between 7-16.3. This data indicates a low level of perception of senior year students for physical bullying when they were $15-18$ year old.

To address the paper question, correlation analyze was conducted. This question has explored if there is any relationship between the perception of students about physical bullying and their age.

Table 3. Spearman's rho coefficient for two variables.

\section{Correlations}

\begin{tabular}{|l|l|l|r|r|}
\hline \multicolumn{2}{|c|}{} & & \multicolumn{1}{c|}{$\begin{array}{c}\text { Physical } \\
\text { Bullying }\end{array}$} \\
\hline \multirow{3}{*}{ Spearman's rho } & \multirow{2}{*}{ Age } & Correlation Coefficient & 1.000 & $-.865^{\star \star}$ \\
\cline { 3 - 5 } & & Sig. (2-tailed) & .000 \\
\cline { 3 - 5 } & & $\mathrm{N}$ & 400 & 379 \\
\cline { 2 - 5 } & \multirow{2}{*}{ Physical Bullying } & Correlation Coefficient & $-.865^{\star \star}$ & 1.000 \\
\cline { 3 - 5 } & & Sig. (2-tailed) & .000 & 379 \\
\cline { 3 - 5 } & & $\mathrm{N}$ & 379 & 3 \\
\hline
\end{tabular}

${ }^{\star *}$. Correlation is significant at the .01 level (2-tailed).

From the data of table № 3 , it was revealed that there is a strong significant negative relationship between two variables, $r s=.-865, n=400, p=.000 ; p<.0005$. This indicates that if the age grows the perception of adolescents about physical bullying during the years decreases.

\section{Conclusions}

In conclusion, some results can be presented at the end of this article. From the survey conducted in the population of senior students who attended high school in Tirana, Shkodra, Elbasan, Durrës and Korça, a sample of 400 students is selected through the stages sampling method. Out of 400 senior students of the high school of the sample, just 168 were boys and 232 girls, or $42 \%$ boys and $58 \%$ girls. The largest number of participants, $79 \%$ was 18 years old, followed by the students who were 19 years old, which comprise $21 \%$ of the entire sample.

Additionally, Cronbach's alpha was run in order to assess internal consistency reliability for the scale used to collect the data. This scale has a good internal consistence, with a Cronbach alpha coefficient reported .74.

A two tailed alpha level of .05 was set a priori for all statistical tests. To answer the question, about the perceptions of the students of the senior year about being physical bullied during the school time and the relationship between this perception and age, frequencies and spearman's rho coefficient analyses, was conducted.

From the statistical analysis it was revealed that there is a strong negative correlation between two variables, $r s=.-865, n$ $=400, p=.000 ; p<.0005$. This indicates that if the age grows the perception of adolescents about physical bullying during the years decreases.

\section{Recommendation}

First of all it is time to understand that bulling is a reality in our schools. All anti-bullying efforts in schools - be they strategies and procedures for dealing with incidents of bullying behavior, or for preventing further incidences, or support services for those involved in bullying behavior - should be underpinned by an overall anti-bullying policy. This should be formulated 
by the responsible members within the school's management staff, in consultation with all groups within the school community - school management staff, classroom staff, nonteaching staff, students and parents of the school's students.

The role of classroom staff in anti-bullying work is the practical and day-to-day implementation of the procedures and strategies specified in the school's anti-bullying policy is really important. At a conceptual level, it is possible to render distinct strategies for dealing with incidents of bullying behavior, and preventative strategies that can be taught/ implemented through specific classroom activities. Practically, all anti-bullying work makes certain skills and personal demands upon members of classroom staff. (O'Moore \& Minton, 2005)

\section{References}

[1] Askew, S. (1989). Aggressive behavior in boys: to what extent is it institutionalized? In Tattum, D. and Lane, D. (eds) Bullying in Schools. Stoke-on-Trent: Trentham Books.

[2] Bowers, L., Smith, P. and Binney, V. (1994) "Perceived family relationships of bullies, victims and bully/victims in middle childhood", Journal of Social and Personal Relationships, 11, pp. 215.

[3] Bronfenbrenner, U. (1979). The ecology of human development: Experiments by nature and design. Cambridge, MA: Harvard University Press, cited by Espelage,L.D \&Swearer,S.M (2009). Bullying in American Schools: A socialecological Perspective on Prevention and Intervention. Retrieved from bookzz.org/book/831971/469f34

[4] Cohen, L, Manion, L \& Morrison, K. (2005). Research Methods in Education (5th Ed.). Taylor \& Francis Group.

[5] Creswell, J.W. (2003). Research Design: Qualitative, Quantitative and mixed method approaches. Thousand Oaks, CA: SAGE

[6] Lee.Ch. (2005). "Preventing Bullying in Schools: A Guide for Teachers and other Professionals", pp. 9-10. Retrieved from bookzz.org/book/841734/efff26

[7] National Center for Injury Prevention and Control. (2011). Measuring Bullying Victimization, Perpetration and Bystander Experiences: A Compendium of Assessment Tools. Retrieved from www.cdc.gov/violenceprevention/pdf/bullyCompendiumBk-a.pdf

[8] O'Moore.M \& Minton,S. J. (2005). Dealing with Bullying in Schools: A Training manual for Teachers, Parents and other Professionals, pp.21. Retrieved from bookzz.org/book/841739/3ff7bf

[9] Pallant.J. (2010). SPSS Survival Manual. (4th Ed.). McGraw-Hill Companies.

[10] Robinson, G. \& Maines, B. (2008). "Bullying: A complete Guide to the Support Group Method". Retrieved from bookzz.org/book/839994/303489

[11] www.anti-bullyingalliance.org.uk 